\title{
Correction to: Fire impacts on a forest obligate: western gray squirrel response to burn severity
}

\author{
Maria Vittoria Mazzamuto ${ }^{1}\left[\right.$ ' Maxwell N. Mazzella ${ }^{1} \cdot$ Melissa J. Merrick $^{1} \cdot$ John L. Koprowski ${ }^{1}$
}

Published online: 6 May 2020

๑) Deutsche Gesellschaft für Säugetierkunde 2020

\section{Correction to: Mammalian Biology

$$
\text { https://doi.org/10.1007/s42991-020-00024-y }
$$

The original version of this article unfortunately contained a mistake. The presentation of Fig. 1 was incorrect. The original article has been corrected.

The original article can be found online at https://doi.org/10.1007/ s42991-020-00024-y.

Maria Vittoria Mazzamuto

mvmazzamuto@email.arizona.edu

1 School of Natural Resources and the Environment,

University of Arizona, Environment and Natural Resources

2, 1064 East Lowell Street, Tucson, AZ 85721, USA 